\title{
El mosaico de Bernard - La explicación causal en biología funcional
}

The Mosaic of Bernard - Cause and Effect in Functional Biology

* Gustavo Caponi

\begin{abstract}
Resumen: Según un punto de vista muy difundido, y alineado con la concepción nómica de la explicación causal, la biología funcional está sometida a un régimen de heteronomía explicativa en cuyo marco los fenómenos orgánicos deben explicarse recurriendo a leyes oriundas de la física y la química. En contra de esa perspectiva, la concepción experimental de la causación permite entender la naturaleza de muchas explicaciones biológicas que, sin hacer referencia a leyes causales - físicas, químicas o de cualquier otra naturaleza se legitiman por el hecho de ponernos en condiciones de controlar experimentalmente fenómenos relativos al funcionamiento y a la constitución de los organismos. Esas explicaciones suponen invariantes locales que muchas veces, pero no necesariamente, podrán llegar a ser caracterizados como instancias de leyes físico-químicas.
\end{abstract}

Palabras clave: heteronomía explicativa, invariantes casuales, leyes causales, James Woodward.

\begin{abstract}
In accordance with a widespread point of view, aligned with the nomological conception of causal explanation, functional biology is subjected to a regime of explanatory heteronomy under which organic phenomena should be explained by using laws of physics and chemistry. Against this perspective, the experimental conception of causation allows us to understand the nature of many biological explanations that, without make any reference to causal laws - physical, chemical or of other nature -, are legitimized because they permit the experimental control of phenomena that have to do with the functioning and development of organisms. These explanations involve local invariants that often, but not necessarily, may be characterized as instances of physical and chemical laws.
\end{abstract}

Keywords: Explanatory heteronomy. Causal invariants. Causal laws. James Woodward.

\footnotetext{
* Profesor Asociado del Departamento de Filosofía de la Universidade Federal de Santa Catarina.
} 


\section{Presentación}

Siempre que se discutió la existencia de leyes biológicas que permitiesen la construcción de explicaciones nomológicas en ciencias de la vida, el foco estuvo en la biología evolucionaria; a veces en la ecología de poblaciones. El conjunto de disciplinas que Mayr (1961) englobó bajo el rótulo de 'biología funcional' - fisiología, biología del desarrollo, biología Molecular, biomedicina, etc. - quedó, generalmente, fuera de discusión. Dicha biología, que es la que estudia los fenómenos que ocurren y pueden ser registrados en el plano del organismo individual, o incluso en el plano de sus componentes más elementales ${ }^{1}$, no parecía plantear mayores problemas a ese respecto; y eso era así porque, de un modo u otro, se aceptó que allí regía lo que Marcel Weber (2004, p. 28) caracterizó como una heteronomía explicativa.

Según dicha tesis, ya tácitamente presente en Mayr (1961) y en Smart (1963), la biología funcional explicaría los fenómenos y procesos por ella estudiados, aplicando, tácita o explícitamente, leyes físicas y químicas. Diferentemente de la biología evolucionaria y de la ecología poblacional (WEBER, 2004, p. 28), la biología funcional, a la que Weber (2004, p. 3) llama 'biología experimental'2, avanzaría siguiendo un proyecto de orientación reduccionista (WEBER, 2004, p. 24) caracterizado por un uso creciente de leyes físico-químicas. "Para explicar los fenómenos biológicos", dice Weber (2004, p. 28), "los biólogos experimentales deben aplicar teorías oriundas de la física y de la química"; y lo cierto es que, cuando se considera el desarrollo de la biología molecular, uno parece obligado a aceptar esa tesis. La heteronomía explicativa de la que habla Weber parece corresponderse con la que ha sido y sigue siendo el vector de progreso de la biología funcional.

Creo, sin embargo, que aceptar esa idea tal y como Weber la presenta, puede conducirnos a dos errores. El primero es el de refrendar la concepción de la explicación causal que dicha idea conlleva: explicar causalmente supondría, ora la referencia directa a leyes causales; ora la referencia a mecanismos cuya operación pueda descomponerse por lo menos en principio - en múltiples procesos causales que sí sean explicables por alusión directa a leyes. El segundo error es el de formarnos

1 Entiendo que la mejor forma de entender la dicotomía entre biología funcional y biología evolucionaria es en términos de una distinción entre una biología de fenómenos organísmicos y una biología de linajes. La primera es la biología funcional; considerándose a la autoecología como parte de ella. La segunda es la biología evolucionaria; incluida la Evo-Devo (cf. CAPONI, 2013).

2 Por mi parte, pienso que la expresión "biología experimental" no corresponde en este caso, porque también existen abordajes experimentales de la biología evolucionaria (FUTUYMA \& BENNETT, 2009) y de la propia ecología (LUBCHENCO \& REAL, 1991). 
una idea inadecuada, e históricamente inexacta, sobre cómo se explica y sobre cómo se legitiman las explicaciones en biología funcional.

Por eso, en contra de ambas cosas, voy a proponer, en primer lugar, que la explicación causal en biología funcional es más inmediatamente comprensible en términos de la concepción experimental, y no en términos de la concepción nómica, de la causación; y será dicha concepción experimental de la causación, sobre todo en la forma que le dio James Woodward (2003), que nos permitirá entender la naturaleza de esas explicaciones biológicas que, sin hacer referencia a leyes causales físicas, químicas o de cualquier otra naturaleza - se legitiman por el hecho de ponernos en condiciones de controlar experimentalmente fenómenos relativos al funcionamiento y a la constitución de los organismos y de los diferentes subsistemas que los componen.

Me permito señalar, además, que la negación de esa supuesta heteronomía explicativa de la biología funcional que aquí ensayaré, tiene consecuencias que trascienden la propia temática de la causación. Negar la heteronomía explicativa de la biología funcional es también afirmar su autonomía epistemológica; y ahí hay más que una cuestión puramente verbal. Si el vínculo causal entre los fenómenos organísmicos puede establecerse con independencia de la legalidad físico-química, eso implica que el fenómeno organísmico puede darse por explicado antes del establecimiento de esa legalidad. La biología funcional, quiero decir, no tiene que ir necesariamente a la saga de la física y de la química; ni tampoco tiene que esperar que esas disciplinas le concedan sus recursos explicativos. He ahí una autonomía, históricamente ejercida, que no se menoscaba por el hecho de que, eventualmente, la explicación físicoquímica venga a complementar o a respaldar a la explicación biológica.

\section{Explicaciones anómicas}

Se podría pensar que el problema que estoy planteando ya fue resuelto por aquellos autores que, como Darden, Machamer y Craver (2006) dejaron de lado el modelo nomológico-deductivo, para comenzar a pensar la explicación biológica en términos de mecanismos. Pero, como Peter Menzies (2012) lo mostró, no es así: aunque ciertamente la imagen de la explicación en biología funcional que proponen esos autores (cf. DARDEN et al., 2006, p. 19) es mucho más adecuada, e iluminadora, que la provista por alguna ejemplificación simplista del modelo nomológico-deductivo, hay una cuestión que la referencia a los mecanismos deja sin resolver: la forma que tomarían las explicaciones de cada uno los procesos causales involucrados en el funcionamiento de esos mecanismos (WOODWARD, 2002, p. 372). Sin desestimar todos los lucros en términos de compresión 
de diversos aspectos de la explicación biológica que la idea de mecanismo puede darnos, creo que esa falta puede ser subsanada recurriendo a la idea experimental de la causación (WOODWARD, 2002, p. 369).

Los mecanismos, según sus promotores los definen, "son entidades y actividades organizadas de forma tal que generan cambios regulares desde un punto de partida o arranque hasta un punto o condición terminal" (DARDEN et al., 2006, p. 14). Los mecanismos son sistemas o procesos causales articulados y concatenados de forma a producir un resultado que, bajo ciertas circunstancias, es previsible. Eso no sólo da lugar para preguntarnos qué es lo que establece los vínculos causales que deben existir entre los distintos eslabones de dichos procesos (cf. Weber, 2004, p. 29); sino que también invita a buscar explicaciones sobre cómo ciertos procesos o fenómenos pueden causar interferencias y desvíos en el funcionamiento de tales mecanismos. Es decir: necesitamos una idea de la explicación causal que sea anterior a la propia idea de mecanismo (cf. CRAVER, 2002, p. 72; GLENNAN, 2009, p. 318); y ahí podemos volver a caer en la idea de la heteronomía explicativa (cf. DARDEN et al., 2006, p. 20; BECHTEL, 2011, p. 537).

Resulta dejar de lado esa idea sin contar con una alternativa clara a la concepción nómica de la causación; y eso es lo que nos provee la concepción experimental que aquí quiero reivindicar (WOODWARD, 2002, p. 375). Ésta brinda una alternativa a la idea de la heteronomía explicativa que, además de ser más radical que la esbozada por Darden, Machamer y Craver, puede también incluirla (MENZIES, 2012, p. 798). La concepción experimental de la causación da una idea de lo que articula y justifica las imputaciones causales presupuestas en el análisis de los eslabones causales de cualquier mecanismo, que es diferente de la concepción nómica de las imputaciones causales (WOODWARD, 2002, p. 371; CRAVER, 2007, p. 93). Eso, en lo que atañe al caso específico de la biología funcional, nos exime de aceptar la tesis de la heteronomía explicativa.

En realidad, todo el problema de las leyes biológicas, en general y no sólo en lo que atañe a la biología funcional, creció a la sombra del modelo nomológico-deductivo de explicación (Woodward, 2003, p. 4). El nudo de la polémica siempre residió en la presunción de que toda explicación causal genuina debía estar, tácita o explícitamente, fundada en una ley causal (cf. HEMPEL, 1979[1965], p. 347). La biología evolucionaria, y también otras disciplinas como la ya mencionada ecología de poblaciones, quedaron así en el centro de la polémica porque en el caso de ellas era difícil identificar los enunciados nómicos que daban forma y soporte a sus explicaciones e imputaciones causales. La biología funcional, en cambio, nunca llegó a recibir tanta atención porque se presumía que su supuesta 
heteronomía explicativa, resolvía todo el problema: sus explicaciones se encajarían perfectamente en ese modelo porque, quizá más tacita que explícitamente, ellas estarían articuladas por leyes físicas o químicas.

Sin embargo, si uno se asoma a las explicaciones causales que efectivamente se construyen en fisiología, en biología del desarrollo, o en dominios biomédicos como la farmacología y la toxicología, se verá que, muchas veces, dichas explicaciones están demasiado lejos de aquello que la tesis de la heteronomía explicativa, nos podría hacer esperar. No es sólo que esas explicaciones no aludan explícitamente a leyes físicas o químicas específicas; sino que, a menudo, ellas aluden, ora en su explanans, ora en su explanandum, o en ambos, a variables caracterizadas en términos puramente biológicos. En muchos casos, reacciones y procesos fisiológicos son explicados en términos de variables fisiológicas, aunque estas puedan estar afectadas por factores físicos o químicos; pudiendo ocurrir lo mismo con procesos embriológicos, celulares, histológicos, e incluso con respuestas a fármacos y tóxicos de los más diversos tipos. Esas explicaciones establecen conexiones causales sin que se atisbe, ni se considere necesario vislumbrar, cuál sería la ley, o el conjunto de leyes físico-químicas, que fundaría esos vínculos de causa y efecto.

Además, aunque después de procure y se consiga profundizar y fundamentar esas explicaciones causales descendiendo a la infraestructura molecular, bioquímica y a veces biofísica, de los procesos biológicos estudiados, realizándose así una démarche que puede merecer el calificativo de reduccionista, lo cierto es que ese descenso a lo molecular no tiene por qué redundar en una rectificación de tales explicaciones menos fundamentales, ni tampoco tiene que considerarse como su imprescindible ratificación. Es decir: esos desarrollos de la biología molecular pueden refrendar las explicaciones biológicas más tradicionales; pero eso no implica que las mismas deban ser consideradas como provisorias o inconclusas hasta no recibir dicho respaldo. Eso, junto con la dificultad para identificar las leyes físico-químicas que articularían tales explicaciones, configura un cuadro que no se lleva del todo bien con la idea de heteronomía explicativa. Por lo menos hasta cierto punto, la biología funcional parece capaz de explicar biológicamente: no física o químicamente.

La teratología nos brinda ejemplos de eso (UJHÁZY et al., 2012). La perturbación de los procesos de inducción embrionaria, que son los responsables de la diferenciación de órganos en la ontogenia, puede generar distintas malformaciones; y esas perturbaciones pueden ser apuntadas como causas de dichas anomalías sin que para ello sea necesario conocer la base molecular de tales fenómenos (GILBERT, 1994, p. 513-515; 
DELSOL \& PERRIN, 2000, p. 88-90). No es que esa base no exista, ni tampoco que su conocimiento no provea una explicación más acabada de esos fenómenos (GILBERT, 1994, p. 527-537). Pero, si se afirma que la estrangulación incompleta de un embrión de salamandra generó un monstruo diencéfalo, y eso se ratifica por una manipulación experimental en la cual se estrangula otro embrión de salamandra, de forma tal que se forme otro monstruo con esas características, nuestra explicación causal de ese proceso de teratogénesis será considerada válida y satisfactoria. Aun cuando la base molecular de la inducción embrionaria fuese totalmente desconocida; y aun cuando nadie pretenda apuntar cual sería la ley física o química de la cual esa relación entre ciertas estrangulaciones del embrión de algunas especies y determinadas malformaciones, sería una instancia o una aplicación.

Del mismo modo, si se explica el crecimiento de los testículos de los patos, que ocurre durante la primavera, diciendo que dicho crecimiento lo genera el aumento de las secreciones de la hipófisis, que es directamente estimulada por la luz solar; esa imputación causal puede ser aceptada y legitimada, aun cuando se ignore la filigrana molecular que permite la estimulación solar de una región cerebral. Esa legitimación puede tomar, otra vez, la forma de una manipulación experimental: si les tapamos los ojos a algunos patos, y eso impide el crecimiento de sus testículos, nuestra explicación causal se verá reforzada (cf. DELSOL \& PERRIN, 2000, p. 88-90). Ese refuerzo aumentará si creamos varios grupos control en los que los ojos de los patos son tapados por periodos más o menos largos y eso se refleja en diferencias en el crecimiento de los testículos que son proporcionales a la duración de la obstrucción, o al bloqueo mayor o menor de la luz solar que ella ejerce.

Tanto aquí como en caso anterior, no se supone ninguna ley de la cual el vínculo causal apuntado sea una instancia; y es la posibilidad de control experimental la que nos lleva a aceptar que ese vínculo existe. No hay una ley física que vincule aumento de luz y aumento en el tamaño de los testículos de los patos. Puede haber, sí, leyes que expliquen cada uno de los eslabones del mecanismo; pero no es el conocimiento de esas leyes lo que justifica la imputación causal "en condiciones normales, la luz solar aumenta el volumen de los testículos de estos patos", sino la posibilidad de usar esa regularidad como receta para manipular el crecimiento de esos órganos en esos animales. Una receta que sería muy importante para una industria de paté de testículo de pato; como seguramente ya lo es para la agricultura la correlación constante entre velocidad germinativa y temperatura que se verifica en las diferentes especies de semillas.

Desiderio Papp (1980, p. 178) la explicaba así: "La velocidad germinativa del grano de trigo depende de la temperatura y alcanza 
su máximo a $28^{\circ}$; por debajo de $5^{\circ}$ y por encima de $37^{\circ}$, la velocidad es nula". Eso configura "una curva bien determinada" que será análoga a la que se den con otros granos; aun cuando los extremos de máximas y mínimas varíen en cada caso. Así, conociendo cuál es esa curva en una determinada semilla, podremos controlar o prever su velocidad de germinación, manipulando o midiendo la temperatura en la que ella se encuentra. Años más fríos, podemos preverlo, nos darán cosechas más tardías; y, llegado el caso, imputaremos ese retraso al frio, aun cuando no conozcamos la ley físico-química que explique esa relación causal de la cual, pese a todo, no dudamos.

Pero, si existe un ejemplo de explicación causal biológica que definitivamente no encaja, ni en la idea de heteronomía explicativa, ni en el modelo nomológico-deductivo en el que ella se recuesta, ese ejemplo es el de la explicación de las enfermedades infecciosas. Tal el caso de la explicación bacteriológica de muchas úlceras gástricas (THAGARD, 1999, p. 59-61); propuesta y aceptada bajo el imperio de la biología molecular, pero atendiendo a coordenadas típicas de la microbiología clásica: la microbiología de Pasteur y de Koch (cf. GRADMANN, 2006, p. 88-90).

En la década que va de 1985 a 1995, los médicos australianos Robin Warren y Barry Marshall consiguieron mostrar que Helicobacter pylori era el agente responsable de muchas de esas úlceras en virtud de tres conjuntos de datos: [1] Evidencia clínica y epidemiológica de la asociación entre dicha bacteria y esa patología; [2] Éxito en la producción experimental de la úlcera por inoculación de cepas puras, cultivadas experimentalmente, de la bacteria imputada; y [3] Evidencia experimental y clínica creciente de cura de la úlcera por el uso de un antibiótico específico (THAGARD, 1999, p. 62-64). Es decir: la úlcera se puede producir inoculando Helicobacter pylori; y se puede curar eliminando a ese agente. Nadie precisa de ninguna ley, y menos de una ley física o química, para justificar las imputaciones causales que a partir de ahí puedan formularse sobre casos clínicos concretos.

No se trata de poner en duda de que, en última instancia, las regularidades causales allí implicadas sean la manifestación local de regularidades más amplias, y fundamentales, de carácter físico-químico: todos somos fisicalistas. Lo que importa es que, en casos como esos, la explicación causal puede prescindir de la referencia a esas regularidades mayores. La posibilidad de controlar experimentalmente tales fenómenos por la manipulación de variables específicamente biológicas, da soporte y fuerza explicativa a esos análisis causales; aunque cuando ellos no tengan fundamento legal. En la fisiología, en la biología del desarrollo, en la teratología, en la microbiología, etc., la experimentación llega antes que la ley. En ellas es la experimentación la que distribuye e instituye las 
imputaciones y las explicaciones causales (cf. BAEDKE, 2012, p. 170). Esas ciencias son, claramente, disciplinas baconeanas, y no galileanas ${ }^{3}$. Allí la mano llega antes que el concepto; pero si atendemos a la concepción experimental de la causalidad, podremos decir que ellas trabajan en base a una idea de la explicación causal que es común a todas las disciplinas científicas. Sólo que en su caso, eso se hace más evidente.

\section{La concepción experimental de la explicación causal}

"La característica distintiva de las explicaciones causales", afirma James Woodward (2003, p. 6), es que ellas "ofrecen información potencialmente relevante para la manipulación y el control: ellas nos dicen cómo, estando nosotros en condiciones de alterar el valor de una o más variables, podríamos modificar el valor de otras". "La idea de hacer", ya lo decía Paul Valery (2002 [1944], p. 549), "es la primera y más humana. Explicar es describir una manera de Hacer: es re-hacer con el pensamiento". Eso lo ilustran las explicaciones en las que recurrimos al Principio de Arquímedes para dar cuenta del empuje que padece un cuerpo inmerso en un líquido: esas explicaciones nos dicen cómo modificar esa fuerza, ora alterando el volumen del cuerpo, ora alterando la densidad del líquido. Pero eso también se cumple cuando nuestras explicaciones aluden a fenómenos que escapan a toda posibilidad de manipulación (WOODWARD, 2009, p. 235). Tal como ocurre cuando citamos una erupción del Vesubio para explicar la destrucción de Pompeya.

"La erupción de un volcán y la destrucción de una ciudad", conforme decía Von Wright (1980, p. 94), "son dos eventos sumamente complejos"; $\mathrm{y}$ "en cada uno de ellos cabe discernir diversos acontecimientos o fases, y distintas conexiones causales entre ellos". Siendo esas conexiones causales particulares las que satisfacen, cada una de ellas separadamente, la concepción experimental de la causación. Tal "el caso de una piedra que, al caer, alcanza a un hombre en la cabeza y lo mata"; o incluso el derrumbe del "techo de una casa bajo un determinado peso" (VoN WRIGHT, 1980, p. 94). Y también la circunstancia de "que un hombre no pueda tolerar el calor por encima de una temperatura en particular" (VON WRIGHT, 1980, p. 94). "En todos esos casos", señalaba Von Wright (1980, p. 94), "tienen lugar relaciones causales que nos resultan familiares por experiencia y en las que el factor-causa satisface típicamente el requisito de ser manipulable".

Sobre las diferencias entre esos dos tipos de ciencias, cf. Kuhn (1977, p. 32ss.). 
De todos modos, los fenómenos que estudia la biología funcional están, todos ellos, al alcance de nuestra capacidad de manipulación y experimentación. De hecho, la mayor parte de la biología funcional es biología experimental ${ }^{4}$. No será por ese lado que encontraremos algún obstáculo que impida pensarla en función de la concepción experimental de la causación. Pero para entender esta última concepción - o mejor: para sacarla de la esfera de nuestro saber pre-teórico, que es donde ella profundamente incrustada, y traerla a la esfera de las tesis filosóficas, explícitamente formuladas -, podemos comenzar con un ejemplo que no será de biología. Aun cuando los ejemplos que dimos en la sección anterior son también ilustraciones claras de esa forma de entender las imputaciones y las explicaciones causales.

Imaginemos que estamos manipulando una vieja radio que ya pasó por muchos y muy descuidados arreglos. Un de los cuales, incluso, resultó en un reposicionamiento del control del volumen cuya ocurrencia inicialmente nosotros ignoramos; siendo que como resultado de esa modificación, dicho potenciómetro ahora opera de modo contrario al habitual. En esa radio miserable, para aumentar el volumen es necesario mover el botón en sentido anti-horario. Por eso nos desconcertamos cuando, al intentar subir el volumen moviendo el control en sentido horario, obtenemos el resultado contrario. Eso, incluso, nos deja momentáneamente con la sensación de haber movido el dial. Los dos únicos controles de ese viejo aparato son del mismo tamaño y ya no cuentan con ninguna indicación sobre función. Con nuestro movimiento, pensamos por un instante, podríamos estar alejando al dial del ponto de sintonía; y no subiendo el volumen, que era lo que habíamos querido hacer.

Esa impresión hasta llega a reforzarse porque, al mover el botón en sentido anti-horario - es decir: en el sentido en el que habitualmente el volumen disminuiría si ese fuese su control - la intensidad del sonido vuelve a subir. Podríamos muy bien estar ressintonizando la señal de la cual habíamos comenzado a apartarnos. Pero esa idea, que apenas se nos pasa por la cabeza, se esfuma rápidamente; porque la relación entre el volumen y el movimiento de ese control no sigue la pauta que debería esperarse de un dial: cuanto más amplio es nuestro movimiento en sentido anti-horario, más alto es el volumen. La sintonía, en cambio, permanece constante, aunque ese movimiento llegue hasta el extremo máximo al que dicho control puede llegar si movido en sentido antihorario. Una sintonía, no lo olvidemos, tiene un ponto óptimo, del cual nos apartaríamos fuese cual fuere la dirección en la que el dial es movido.

4 Pero no toda: un estudio epidemiológico, puramente comparativo, sobre los efectos cancerígenos del tabaco es parte de la biología funcional. 
Por otro lado, la relación entre el volumen y los movimientos del control que manipulamos, es regular: prácticamente constante. Salvo la perturbación que puede producir un cambio en la posición del aparato, y fuera del efecto ocasionado por una u otra interferencia, siempre que movemos ese control en sentido anti-horario, el volumen aumenta, disminuyendo gradualmente hasta el silencio, cuando el movimiento es en sentido horario. Más aún: la relación entre ese movimiento y el nivel del volumen guarda una proporción que también es bastante regular. Cuanto más amplio y más rápido es el movimiento del potenciómetro, en un sentido o en otro, mayor y más brusca es la alteración del volumen. En cambio, si el movimiento es lento, esa alteración sonora también ocurrirá lentamente; y es ahí, cuando establecemos esa correlación (hasta donde pudimos ver) invariante entre nuestras manipulaciones de ese botón y el volumen sonoro, que nuestras dudas desaparecen. Ese botón, concluimos suspirando, sólo puede ser un control de volumen que, por alguna razón desconocida, funciona de modo opuesto al habitual.

Podemos no estar en condiciones de explicar una relación causal. Podemos ignorar cómo, por la mediación de cuál mecanismo, las posiciones de un botón determinan el volumen de sonido emitido por una radio. Pero eso no nos deja sin fundamento para considerar que los movimientos en sentido horario y anti-horario de ese botón causan los cambios de volumen. Tal como ocurrió, por otro lado, con la función del páncreas: el papel causal de ese órgano en la digestión de la gordura fue establecido, aun sin que supiésemos cuáles eran los mecanismos fisiológicos y bioquímicos que explicaban la mayor presencia de gordura no digerida en la materia fecal de los perros en los cuales se impedía el funcionamiento de esa glándula (cf. Romo, 2006, p. 103). Que no podamos explicar una relación de causa-efecto no implica que ella no pueda ser invocada para operar, ella misma, como clave de la explicación causal de un evento.

Que un agricultor ignore qué es lo que explica la relación entre temperatura y velocidad de germinación, no lo impide de explicar la tardanza en la germinación de su sembradío después de un invierno demasiado frio. Incluso si no hubiese otro conocimiento sobre esa correlación que fuese más allá de la evidencia experimental, provista por nuestra capacidad de controlar experimentalmente la velocidad de germinación manipulando la temperatura en la se encuentran las semillas, aun así esa explicación sería válida. Como es válido atribuir una úlcera al accionar de Helicobacter pylori, aun cuando no sepamos cómo es que esas bacterias dañan el tejido gástrico. Podemos desconocer el mecanismo de la lesión y aun hacer decir: la infección por Helicobacter pylori es su causa. La cura por el antibiótico nos dará la razón. 
O volviendo al ejemplo de la radio: que yo ignore, como de hecho ignoro, el mecanismo que permite que los potenciómetros regulen el volumen de los aparatos de audio, e ignore también por qué ese viejo y maltrecho receptor tiene su control del volumen invertido, no implica que yo esté impedido de explicar un aumento del volumen de ese aparato, diciendo que eso ocurrió porque yo mismo moví la perilla indicada en dirección anti-horaria. Si alguien me pregunta por qué el volumen aumentó, podré aun responder, impávido: 'Porque moví el control del volumen en sentido anti-horario'. Estaré dando una impecable explicación causal de lo acontecido. Una explicación que podrá ser corroborada mostrándose que, si volvemos ese controle para su posición anterior, el volumen también decrece.

Pero, lo que ahí funcionará como prueba crucial de la corrección y pertinencia de esa explicación causal es que, repitiendo el movimiento en sentido anti-horario del control en cuestión, el volumen aumentará nuevamente. 'En este viejo y maltratado aparato, el volumen crece si el botón negro es movido en sentido anti-horario y decrece si ese movimiento se hace en sentido contrario': he ahí un principio de funcionamiento específico de ese receptor particular; un principio que se instaló como base de explicaciones causales del comportamiento de ese aparato. No de todos los aparatos de radio, pero sí de ese aparato enclenque que tengo entre las manos y que es el único con el que cuento, en ese momento, para escuchar el inminente match Argentina-Brasil. Llegamos así a un tema clave.

Llegamos a una noción que es crucial para la concepción experimental de la causación: aludo a eso que Woodward (2002, p. 370; 2003, p. 14-15) llama 'invariancia' o 'invariante' (PSILLOS, 2002, p. 182-183). Los estados de una variable sólo pueden ser controlados por intermedio de la manipulación de los estados de otra variable, que sea realmente distinta de la primera, si entre esos estados existe una asociación constante tal que pueda preverse la modificación que ocurrirá en la variable controlada en virtud de nuestro conocimiento de la modificación que introduciremos en la variable de control (WOODWARD, 2010, p. 291-292). Podemos afirmar que existe una relación causal entre un cambio ocurrido en una variable $X$ y un cambio ocurrido en otra variable $Y$, solamente bajo la hipótesis de la existencia de una relación virtual, latente, pero mínimamente constante, invariante, entre los cambios y estados de $X$ y los cambios y los estados de $Y$ (WOODWARD, 2003, p. 15-17).

Cuando manipulábamos la miserable la radio de nuestro ejemplo, el descubrimiento de que aquél potenciómetro, pese a su comportamiento inicialmente desconcertante, era el control del volumen y que el nivel de éste dependía de las posiciones de aquél, coincidió el establecimiento de 
este invariante: si movemos este control en sentido anti-horario, el volumen aumenta, y lo movemos en sentido horario, el volumen disminuye. En el funcionamiento de ese castigado aparato, esa anomalía era una regla, una constante; y era esa constante, que no deja de ser una regularidad específica del comportamiento de esa radio, que daba soporte a la certeza de que los cambios de volumen eran producidos por nuestras manipulaciones de ese control. "Las regularidades invariantes", conforme dice Jani Raerinne (2013, p. 847), "describen relaciones de dependencia que pueden ser usadas para manipular cosas. Una regularidad invariante describe que pasaría con el valor de una variable presente en una regularidad o relación, si el valor de una o más variables fuese alterado por intervención o manipulación".

Hay una regularidad invariante entre ciertas intervenciones, mecánicas o químicas que pueden hacerse en un embrión, y ciertas malformaciones que se manifestarán en un momento posterior de la ontogenia. Hay también una regularidad invariante entre la temperatura a la que se somete una semilla y su velocidad de germinación; y como Papp nos mostró, ella hasta puede expresarse en una curva matemática constante para cada especie o variedad de semilla. Hay, por fin, una regularidad invariante que permite correlacionar la mayor estimulación lumínica padecida por un pato, con el volumen que pueden alcanzar sus testículos; y esto es así aunque poco sepamos del mecanismo fisiológico que intermedia entre el input lumínico y el output testicular.

Las leyes causales como el Principio de Arquímedes son, claro, invariantes: son un tipo de invariantes; y eso nos lleva a aceptar que: "en lugar de pensar a todas las generalizaciones causales como siendo leyes", debemos entender a "las leyes como siendo solamente un tipo de generalización invariante" (WOODWARD, 2003, p. 17). Eso es así porque la noción de invariante no está necesariamente vinculada a la de universalidad. Las regularidades invariantes pueden ser de validez puramente local (WOODWARD, 2003, p. 17). Pueden estar referidas a ciertos linajes particulares de seres vivos, como vertebrados en general o patos de ciertas especies. Pueden referirse a ciertas úlceras; y si se trata de la relación entre temperatura y velocidad de germinación, se puede decir que hay un invariante para cada variedad de semilla.

Pero los invariantes pueden estar referidos a un único caso; como en el ejemplo de nuestra radio. Ahí nuestras imputaciones causales no se basaron, ni siquiera, en la presuposición de que en todas las radios en las que el potenciómetro del volumen estuviese posicionado de una determinada forma, la intensidad del sonido aumentaría si dicho control fuese movido en sentido anti-horario. Lejos de eso, nuestras explicaciones causales de las sucesivas alteraciones del volumen, se basaron en un 
invariante referido sólo a ese aparato: en él, el volumen aumentaba si el control respectivo era movido en sentido anti-horario y decrecía si el movimiento ocurría en el sentido opuesto. Hasta donde queríamos saber, eso nos bastaba.

Los estados de cosas conectados por un invariante causal no tienen por qué ser comprendidas como ejemplos de clases naturales: ellas pueden ser designadas por nombres propios o por descripciones definidas (RAERINNE, 2013, p. 847). No es necesario, además, que esos invariantes tengan algún grado significativo de integración teórica (WOODWARD, 2003, p. 17), ascendente o descendente: no es imprescindible que se deduzcan de un cuerpo mayor de teoría, aunque en muchos casos eso sea un objetivo cognitivo pertinente; ni tampoco tenemos que esperar que cumplan algún papel de integrador o sistematizador dentro de un marco conceptual determinado. Esto último, al igual que la universalidad, es algo que exigimos de las leyes, incluso de las que no son causales (LORENZANO, 2007, p. 208); pero no tenemos por qué exigirlo de toda generalización causal. Éstas pueden valer para un único sistema y solamente durante el lapso de tiempo en el que ese sistema exista, o presente la configuración que lo hace comportar de una determinada manera.

Se puede pensar, así, en un amplio espectro de invariantes causales que iría de aquellos más restrictos, que se aplican a un sistema particular e, inclusive ahí, solamente en algunas circunstancias, hasta los más generales y de aplicación más universal; que son los que llamamos leyes causales. Las clausulas ceteris paribus que definen la aplicación de dichas leyes podrán ser, a su vez, más o menos restrictivas; y de eso dependerá la ubicación de las leyes que las incluyan, en los rangos superiores del espectro de universalidad (WOODWARD, 2003, p. 242). Cerca del primer extremo estaría el olvidable invariante de nuestra radio; y cerca del otro extremo estaría el glorioso Principio de Arquímedes. Aunque, importa subrayarlo, esa universalidad no dependa sólo de la extensión de la clase de objetos a la que ella se aplica; sino también de la variedad de circunstancias en la que ella se cumple (WOODWARD, 2003, p. 257).

La relación entre, de un lado, el volumen de un cuerpo y la densidad del liquido en el cual él está inmerso, y, del otro lado, el empuje que dicho cuerpo padece, es más contante y estable que la relación entre los movimientos de un potenciómetro en una radio y sus cambios de volumen sonoro. Si la entrada de energía en la radio está decreciendo, podrán ocurrir disminuciones de volumen totalmente independientes de las posiciones de ese potenciómetro; y si la señal captada es irregular ocurrirán oscilaciones de volumen cuya intensidad tampoco podrán explicarse por dichas posiciones. Ni que hablar, por otra parte, de todos 
los desperfectos internos al circuito de la radio que pueden perturbar su funcionamiento, conspirando contra el cumplimiento de nuestro humilde invariante. Éste es definitivamente menos estable, menos confiable, que el Principio de Arquímedes.

Las leyes físicas que podamos usar para explicar el modo en que se conectan los movimientos de un potenciómetro y el nivel del volumen emitido por una radio, también serán, ciertamente, más estables, más profundas y más explicativas, que el invariante 'si el botón negro de mueve en sentido anti-horario el volumen de esta radio aumenta'. Éste último podría dejar de cumplirse por muchas y muy variadas contingencias; esas leyes, en cambio, se continuarían cumpliendo aun en esas circunstancias y hasta nos servirían para explicar lo ocurrido. Pero, que esas leyes sean más profundas, más estables, y hasta más explicativas que nuestro módico saber sobre cómo controlar el volumen de una radio, no significa, como ya dije, que este último no pueda citarse para explicar causalmente una disminución o un aumento de volumen.

El enfoque experimental de la causalidad, permite entender, en efecto, "como una generalización es capaz de desempeñar una función explicativa aunque eso ocurra solamente dentro de cierto dominio o en un intervalo espaciotemporal limitado, teniendo excepciones fuera de ahí" (WOODWARD, 2003, p. 240). Posibilidad esa que es crucial para reconocer el carácter causal de las explicaciones que encontramos en ciencias especiales como esas que componen el universo de la biología funcional. Eso no lleva a negar que en física o en química existan "generalizaciones que sean legítimamente consideradas como leyes" (WOODWARD, 2003, p. 240); pero nos permite pensar que la explicación causal puede construirse en base a regularidades causales que no presentan los atributos, típicamente nómicos, de universalidad e integración teórica.

\section{Distribuciones contingentes y regularidades causales}

La distinción que Kenneth Waters (1998) trazó entre dos tipos de generalizaciones biológicas, las distribuciones contingentes y las regularidades causales, puede ser refrendada y clarificada a partir de esa idea de invariante que Woodward pone en el centro de su concepción de las explicaciones e imputaciones causales. Pero ella, la distinción de Waters, también puede darnos una oportunidad para formular con mayor claridad las tesis de Woodward; mostrando cómo es que ellas permiten reconocer la capacidad de legitimar y articular explicaciones causales que poseen ciertas generalizaciones biológicas que, desde el punto de vista de la concepción nómica de la causación, nunca podrían ser reconocidas como el elemento estructurador fundamental de ningún explanans causal. 
En cierto sentido, las distribuciones contingentes a las que Waters alude, son a las regularidades causales, lo que las leyes de asociación de Nancy Cartwright son a las leyes causales como el Principio de Arquímedes. Las leyes de asociación son esos enunciados que "dicen cuán frecuentemente dos cualidades o dos cantidades están asociadas"; pero sin establecer ningún vínculo causal entre ellas (CARTWRIGHT, 1983, p. 21). Las distribuciones contingentes, por su parte, informan cuán frecuentemente dos cualidades o cantidades biológicas están asociadas; sin tampoco establecer un vínculo causal entre ellas. Las mismas están articuladas por cuantificadores como todos, ningún, casi todos, raramente o en general.

Las generalizaciones 'Casi todos los urubúes son negros' y 'El albinismo es infrecuente entre los urubúes', son ejemplos de esas distribuciones contingentes. Ya la generalización 'La ausencia de melanina causa albinismo' es una regularidad causal; como también lo son: 'El incremento de la actividad física acelera el ritmo cardíaco' y 'La exposición prolongada al sol oscurece la piel'. Mientras tanto, la afirmación 'En general, los descendientes de japoneses que viven en Brasil tienen la piel más oscura que sus parientes de Canadá', es una distribución contingente: la descripción de un hecho que pide una explicación, que quizá pueda ser dada por esa regularidad causal que vincula la exposición al sol con el oscurecimiento de la piel.

Las distribuciones contingentes son objetos muy familiares y poco problemáticos para la filosofía de la ciencia. Generalizaciones como 'todos os cuervos son negros' son los ejemplos típicos de esa universalidad accidental, carente de contenido causal y de poder explicativo. Siempre fue cómodo contraponerlas a las leyes para así resaltar el valor explicativo y el contenido causal de éstas. El problema está en las regularidades causales. Por un lado, es obvio que ellas no son enunciados universales como el Principio de Arquímedes. 'El incremento de la actividad física acelera el ritmo cardíaco' y 'La exposición prolongada al sol oscurece la piel' valen sólo para algunos taxones. Es decir: sólo se aplican a ciertas entidades particulares; y por eso su estatuto de leyes fue reiteradamente negado (HULL, 1986). Pero, como Waters (1998, p. 18-20) señala, ellas tienen peculiaridades que las aproximan a las leyes. Papp (1980, p. 178), por ejemplo, tomó la regularidad causal que vincula temperatura y velocidad de germinación, como si ella fuese un ejemplo de ley biológica; y eso es entendible.

Las generalizaciones causales tribuyen a determinados objetos disposiciones para comportarse de una determinada manera; soportan predicciones contrafácticas; y hasta puede decirse que su validez no está espaciotemporalmente restringida. La primera de esas peculiaridades 
es bastante obvia. Cuando decimos que la actividad física incrementa el ritmo cardíaco, le atribuimos al corazón una pauta de reacción y formulamos una predicción condicional del tipo: 'si corremos, nuestro ritmo cardíaco se acelera'. Enunciado ese que no sólo será invocado para explicar la aceleración del ritmo cardíaco sufrida por Tomatis después de correr para cruzar la calle bajo la lluvia; pero que también estará en juego cuando se afirma que Pichón habría sufrido síntomas semejantes si hubiese emprendido la misma corrida en lugar de haberse quedado para pagar la cuenta en el bar de la estación. Ya la no restricción espaciotemporal de ese tipo de enunciados no parece tan fácil de aceptar; pero creo que la reconocemos al suponer que, cumplidas ciertas cláusulas ceteris paribus, la correlación entre velocidad de germinación y temperatura se mantendrá más o menos constante en todas partes. Vale en la Tierra y valdría en Marte. Malgré Ray Bradbury.

Lo cierto, por fin, es que las regularidades causales apuntadas por Waters, que son sólo un tipo particular de invariante causal, son permanentemente utilizadas en la articulación de explicaciones causales que pueden ser representadas por un esquema que no está demasiado lejos del modelo nomológico-deductivo. Si aceptamos que la actividad física incrementa el ritmo cardíaco y constatamos que el ritmo cardíaco de Tomatis se fue incrementando a medida que transcurría la prueba de capacidad aeróbica a la que se sometió después del episodio en la terminal de Santa Fe, y que ese aumento estaba asociado al incremento en la intensidad de los ejercicios; entonces será difícil rechazar la validez de esta explicación causal:

Explanans:

Regularidad causal: la actividad física incrementa el ritmo cardíaco. Condición inicial // Descripción de la causa explicante: En el lapso de tiempo $t$, Tomatis incrementó la intensidad de su actividad física.

Explanandum [descripción del efecto explicado]:

En el lapso de tiempo $t$, el ritmo cardíaco de Tomatis se incrementó (proporcionalmente a ese incremento de la intensidad de la actividad física por él desplegada).

El isomorfismo entre esa explicación, basada en una simple regularidad causal biológica, y una posible explicación claramente nomológica, fundada en una ley causal, obedece a una razón importante. Ambos tipos de explicaciones son explicaciones causales articuladas en virtud de eso que Woodward llama 'invariantes causales'. Las leyes causales, como vimos, son invariantes de aplicación más irrestricta, y las regularidades causales a las que se refiere Waters son invariantes de aplicación restricta. 
Pero, aún así, estas últimas ponen en evidencia relaciones causales que cumplen perfectamente con aquello que la concepción experimentalista de la causación nos lleva a esperar de un vínculo causal. Que la actividad física incrementa el ritmo cardíaco, y que el aumento del ritmo cardíaco de Tomatis que estamos registrando, se debe al aumento de su actividad física, son cosas que podemos corroborar por medio de manipulaciones relativamente simples. Podemos disminuir ese ritmo cardíaco haciendo que Tomatis se siente, y podemos volver a incrementarlo, gradualmente y de forma controlada, en virtud de un nuevo aumento, gradual y también controlado, de esa actividad física.

Pero, si hay algo que la distinción de Waters entre distribuciones contingentes y regularidades causales nos deja ver con claridad, es la importancia de la idea de invariancia bajo intervenciones (WOODWARD, 2003, p. 17). Ella es central para caracterizar un invariante causal (BAEDKE, 2012, p. 156); y las distribuciones contingentes son ejemplos posibles de invariantes que no son estables bajo intervenciones: que se quiebran ante cualquier tentativa de usarlos como pauta de ordenadora de una operación de control técnico o experimental. "Cuando una relación es invariante bajo por lo menos algunas intervenciones", dice el propio Woodward (2003, p. 16), "ella es potencialmente usable con propósitos de manipulación y control"; y eso muestra que ella, diferentemente de lo que ocurre con las distribuciones contingentes, reamente alude a una relación causal. Woodward (2003, p. 241-242) explica esa idea de la siguiente manera:

Supongamos que observamos una asociación o una correlación entre $\mathrm{C}$ y E. Si cada intervención que cambia el valor de $\mathrm{C}$ rompe cualquier correlación entre $\mathrm{C}$ y $\mathrm{E}$ (esto es: $\mathrm{C}$ y F devienen no correlacionadas bajo esa intervención), no será posible usar $\mathrm{C}$ para controlar o manipular $\mathrm{E}$, y no consideraremos la relación entre $\mathrm{C}$ y E como causal. Si, por el contrario, la asociación entre $\mathrm{C}$ y E continúa vigente (o invariante) bajo por lo menos algunas intervenciones que cambian C, entonces (si los cambios en $\mathrm{C}$ están asociados con diferentes valores de $\mathrm{E}$ ) estaremos habilitados para usar de esa estabilidad para producir cambios en E para producir cambios en C. Más aún, siendo otras cosas igual, cuánto mayor el espectro de esos cambios bajos los cuales la relación es invariante, más ella será explotable para propósitos de manipulación y control.

Por mi parte, creo que una versión modificada del juego de las bolitas al que Sober (1984, p. 99) alude para explicar la diferencia entre un proceso causal como la selección por y un proceso no causal como la selección de, también sirve para mostrar esa distinción entre correlaciones invariantes bajo intervenciones y correlaciones que no lo son. No se trata 
de una casualidad. La idea de selección de alude a la consecuencia de un proceso causal: alude a una distribución contingente. La selección por alude a lo que pauta, o rige, un proceso causal: alude a un invariante. Pero eso tiene que ver con biología evolucionaria y aquí hablamos de biología funcional; hablamos de invariantes que se registran en el plano de las causas próximas y no de aquellos que se registran en el plano de las causas remotas. Vamos, entonces, a nuestra versión del juego.

Imaginemos que tenemos una bolsa de bolitas de madera que incluye bolitas de color verde de un centímetro cúbico y bolitas de color rojo de un centímetro cúbico y medio; y que dado que no tenemos mejor cosa para hacer porque la radio finalmente se rompió, las hacemos pasar por una suerte de colador que sólo deja pasar a las primeras. Si hacemos eso, en la distribución final de las bolitas se cumplirán dos correlaciones: [1] Las bolas rojas son retenidas por el colador pero las verdes no lo son; y [2] Las bolas grandes son retenidas por el colador pero no las chicas. Más aún: si repetimos la operación varias veces, esas correlaciones se mantendrán y podremos caracterizarlas como invariantes del comportamiento del sistema bolitas-colador. Existe, sin embargo, una diferencia obvia entre [1] y [2]: sólo esta última es una correlación, o un invariante, realmente causal. Es decir: mientras la correlación entre color y posibilidad de pasar o no por el colador es accidental, no-causal, la correlación entre el tamaño y esa posibilidad sí es causal. Eso lo podemos comprobar mostrando que, mientras esta última correlación es invariante bajo ciertas intervenciones, la primera no lo es.

Si pinto a todas las bolas de verde, las mayores seguirán sin atravesar el colador y así se romperá la correlación entre el color y la capacidad de pasar por los agujeritos de ese instrumento. Pero, si agrando los agujeros del colador lo suficiente, las bolas rojas van a pasar por ellos aun sin ser verdes. La relación entre tamaño y capacidad de pasar por los agujeros del colador se habrá mantenido y la correlación entre el color y esa capacidad, otra vez, se habrá perdido. La correlación [2] entre el tamaño de las bolas y la capacidad de pasar por colador se conserva en las intervenciones sobre los orificios de ese instrumento: es una regularidad causal. La correlación entre el color y esa capacidad, en cambio, no se conserva en intervenciones sobre dicho color: es una distribución contingente.

Los invariantes accidentales se rompen fácilmente cuando las variables por ellas correlacionadas son manipuladas (cf. WOODWARD, 2003 p. 259). En cambio, los invariantes causales resisten mejor esas manipulaciones. Por eso Woodward (2003, p. 16) afirma que la idea de invariancia bajo intervenciones está llamada a cumplir la tarea de distinguir entre generalizaciones causales y accidentales que, en otros enfoques de la explicación causal, es desempeñada por la noción de ley 
de la naturaleza. En la concepción experimental de la causación, [2] es a [1], lo que el Principio de Arquímedes es a "todos los salvavidas del Titanic eran de corcho" en la concepción nomológica de la causación y de la explicación causal.

Pero, como el ejemplo de la radio ya lo mostró, y Woodward (2003, p. 17) lo apunta, el hecho de que una generalización sea o no causal "es llamativamente independiente de si ella satisface o no muchos de los criterios tradicionales de nomicidad, tales como la ausencia de excepciones, la amplitud de alcance, y el grado de integración teórica". Woodward (2003, p. 266) afirma, incluso, que: "la mayor parte de esos criterios no son útiles, ni para entender qué es lo distintivo de las leyes, ni para entender las características que caracterizan a las generalizaciones explicativas, sea en el caso de las ciencias especiales o en disciplinas como la física o la química". Bajo este punto de vista, el mayor poder explicativo, causal, del Principio de Arquímedes no deriva de su universalidad, sino de su estabilidad e invariancia bajo intervenciones.

Como dice Woodward (2003, p. 259): "es la invariancia y no la nomicidad que es crucial para la explicación". "La noción de invariancia es más adecuada que la de nomicidad para capturar las características distintivas de muchas generalizaciones que describen relaciones causales y que figuran en explicaciones" (WOODWARD, 2003, p. 17); y "parte del atractivo de la noción de invariancia es que ella promete un tratamiento más satisfactorio de las generalizaciones en las ciencias especiales que la oposición ley-accidente" (WOODWARD, 2003, p. 240). No siendo como el Principio de Arquímedes, los invariantes involucrados en las explicaciones causales de esas ciencias, pueden quizá ser como el principio que rige el control del volumen de nuestra radio. La estabilidad bajo intervenciones de los invariantes causales puede ser mayor o menor; y su fuerza explicativa, insisto, es directamente proporcional a esa estabilidad.

\section{El mosaico de Claude Bernard}

Nancy Cartwright (1999, p. 31) sugirió la alternativa de pensar al mundo como pautado por un mosaico (patchwork) de leyes; y propuso llamar a esa posición 'pluralismo nomológico metafísico': "la doctrina según la cual la naturaleza está gobernada, en diferentes dominios, por diferentes sistemas de leyes, no necesariamente relacionados entre sí, de forma no sistemática o uniforme". Ese pluralismo se opondría al fundamentalismo: posición que consistiría en pensar al mundo como ordenado por un sistema único de leyes cuya base estaría en unas pocas leyes fundamentales o en una única ley totalizadora. Las tesis 
de Woodward sobre la causación, por su parte, permiten pensar al mundo como sujeto a un heteróclito mosaico de invariantes causales. La naturaleza estaría gobernada, en diferentes dominios y en diferentes momentos, por distintos invariantes - algunos de ellos de rango nómico - que no obedecen a una ordenación sistemática o uniforme.

Independientemente de lo que pueda decirse a ese respecto cuando se piensa en las leyes físicas, creo que cuando aludimos a los invariantes que rigen a los fenómenos organísmicos, la idea del mosaico de invariantes parece definitivamente más plausible que el fundamentalismo. La biología teórica puede aspirar legítimamente a elucidar los principios fundamentales que regulan la organización (ELSASSER, 1987, p. 24) y la forma de todos los seres vivos (cf. WEBSTER \& GOODWIN, 1996, p. 125); pero no creo que nadie espere que la miríada de invariantes que gobiernan los más diversos fenómenos organísmicos y sub-organísmicos, puedan transformarse en teoremas de los axiomas de una teoría general del organismo.

Carl Craver (2007, p. 228) ya usó la imagen del mosaico para caracterizar el desarrollo de la neurociencia y el modo en el que dentro de ella se van articulando los resultados de las más diversas investigaciones. Yo creo que esa imagen vale para toda la biología funcional. Las disciplinas baconianas y galieanas no sólo se distinguen por la mayor importancia que unas le dan al control experimental de los fenómenos y otras a la subsunción de esos fenómenos dentro de grandes marcos teóricos; sino que también se distinguen por su modo de desarrollo: las ciencias baconianas avanzan por acumulación de resultados, construyendo paso a paso un amplio mosaico; las ciencias galileanas parecen avanzar por grandes unificaciones teóricas. Éstas dan esperanzas al fundamentalismo; las primeras se llevan bien con un mundo modular, y, así, manipulable.

Como sea, lo cierto es que el conocimiento de la biología funcional realmente existente es, básicamente, una acumulación, no muy sistemática, de esos invariantes; y era a una parte de tales invariantes a los que aludía Claude Bernard (1984 [1865], p. 109) cuando se refería a leyes específicamente fisiológicas. Para él una ley no era más que "una relación numérica invariable entre dos fenómenos" (BERNARD, 1984 [1865], p. 128). Cualquier regularidad causal, formulable como una correlación matemática constante, que permitiese controlar la ocurrencia, la intensidad y la frecuencia del efecto, manipulando la ocurrencia, la intensidad y la frecuencia de la causa (BERNARD, 1984 [1865], p. 108), sería, bajo ese punto de vista, una ley. Sin estar muy preocupado con la universalidad de la correlación causal establecida por una regularidad fisiológica, Bernard estaba dispuesto a llamar a 'ley' a cualquier invariante causal; aun cuando el mismo valiese para un único taxón. 
Para Bernard, ciertamente, la correlación entre ritmo cardiaco y actividad física era una ley fisiológica. La cuestión terminológica, sin embargo, es aquí secundaria, y puede ocultarnos una cuestión epistemológica más interesante. Sin negar que todo fenómeno fisiológico pudiese ser explicado en virtud de causas próximas de carácter puramente químico y físico (Dutra, 2001, p. 5), y sin querer desmarcarse de un encuadramiento fisicalista, Claude Bernard (1984 [1865], p. 110) también insinuaba un punto de vista sobre la explicación causal fisiológica contrario a la supuesta heteronomía explanatoria de la biología experimental (cf. GOODFIELD, 1987, p. 137-139). Para él, explicar en fisiología era situar un fenómeno dentro de un invariante que permitiese su control experimental.

\section{Colofón: la cuestión del reduccionismo}

Negar la heteronomía explicativa de la biología funcional no implica desconocer que muchas de las explicaciones causales formuladas en ese dominio de investigación estén articuladas por invariantes locales que pueden llegar a ser considerados como casos, o aplicaciones, de leyes físico-químicas; aunque eso no sea condición sine qua non para que tales invariantes puedan ser considerados explicativos. Pero, además de ser compatible con el reconocimiento de la posibilidad de ese tipo de vinculación entre conocimiento biológico y conocimiento físico-químico, la negación de la heteronomía explicativa de la biología funcional, también es compatible con el reconocimiento de que, muchas veces, ese descenso a lo físico-químico, a lo más básico, puede ser considerado como progresivo y lucrativo en términos cognitivos.

Muchas veces, tal como Woodward (2010, p. 317) lo ha señalado, los invariantes causales encontrados en las diferentes ciencias especiales son menos estables bajo manipulación, y menos precisos, que los invariantes físico-químicos. Por eso, en esas ciencias puede ser útil apelar a esos invariantes más básicas y más estables para así explicar los fenómenos en estudio. Podemos decir que las generalizaciones fundadas en propiedades más fundamentales son comúnmente, aunque no siempre, más estables y más precisas que las generalizaciones formuladas en términos de propiedades más sobrevenientes (cf. MITCHEL, 2009, p. 58). Pero eso no implica que dicho recurso a lo más básico sea el objetivo explicativo fundamental de esa ciencia especial. Si el biólogo desciende a la infraestructura molecular del fenómeno biológico; lo hace, no con el objetivo de disolver dicho fenómeno en la legalidad físico-química, sino sólo para explicar ese fenómeno biológico en tenemos de invariantes causales más precisas y estables. 
Bajo esta última perspectiva, la física y la química serían solamente instrumentos de la biología; y es posible que, en ocasiones, ese descenso a la infraestructura molecular sea cognitivamente contraproducente: si ese descenso es medio y no fin, eso puede ocurrir. En algunos casos, quizá, mantenerse en el nivel de las propiedades propiamente biológicas puede permitirnos establecer relaciones causales más estables y un control de los fenómenos más afinado que el que nos permitiría el recurso a las propiedades más simple y elementales. Eso es lo que sostuvo Walter Elsasser (1987, p. 143), apelando no ya a un vitalismo trasnochado, sino a la más pura y simple experiencia laboratorial; y, también, a consideraciones sobre nuestras capacidades de computar la información que tendría que ser llevada en cuenta para dar una explicación molecular de fenómenos realmente organísmicos.

La perspectiva de Woodward permite abrir un crédito de plausibilidad a esa posición. Si hay explicación causal sin ley, podemos negar que la única posibilidad de explicar los fenómenos biológicos esté en las leyes que para ese fin presten la física o la química. Además, si la llave de la explicación no está en la propia legalidad, y sí en la estabilidad bajo manipulaciones experimentales, se puede llegar a pensar que, en ocasiones, y dependiendo de qué es lo que en cada caso queremos realmente saber, la estrategia reduccionista puede no ser la más promisora. El descenso a lo molecular puede impedirnos ver invariantes causales que se serían más visibles en un nivel menos básico (cf. CRAVER, 2007, p. 227): más propiamente organísmico.

El verdadero objetivo cognitivo de toda la biología funcional es entender el funcionamiento y la constitución del organismo; y no mostrar su (por nadie discutida) sujeción a la legalidad físico-química. Eso ya lo había apuntado el propio Claude Bernard (1984 [1865], p. 137); y las argumentos que a ese respecto formularon Kurt Goldstein (1951, p. 340) y Merleau-Ponty (1953, p. 215) siguen vigentes. La posibilidad de que existan casos en los que las explicaciones no-reductivas cumplan mejor con ese cometido que las explicaciones moleculares, ya alcanza para desmentir la heteronomía explicativa de la biología funcional. Porque así ya estamos reconociendo que la estrategia reduccionista es, conforme dije, medio y no fin, de ese universo de las ciencias biológicas.

\section{Referencias}

BAEDKE, J. Causal Explanation beyond the Gene: Manipulation and Causality in Epigenetics. In: Theoria 74, (2012), p. 153-174.

BECHTEL, W. Mechanism and Biological Explanation. In: Philosophy of Science 78, (2011), p. 533-557. 
BERNARD, C. Introduction a l'étude de la Médicine Expérimentale. Paris: Flammarion, 1984 [1865].

CAPONI, G. El concepto de presión selectiva y la dicotomía próximo-remoto. In: Aurora 25(36), (2013), p. 197-216.

CARTWRIGHT, N. How the Laws of Physics Lie. Oxford: Oxford University Press, 1983.

.. The Dappled World. Cambridge: Cambridge University Press, 1999.

CRAVER, C. Structure of Scientific Theories. In: MACHAMER, P.; SILBERSTEIN, M. (eds.). The Blackwell Guide to Philosophy of Science. Oxford: Blackwell, 2002, p. 55-79.

CRAVER, C. Explaining the Brain. Oxford: Clarendon Press, 2007.

DARDEN, L.; MACHAMER, P.; CRAVER, C. Thinking about Mechanisms. In: DARDEN, L. (ed.). Reasoning in Biological Discoveries. Cambridge: Cambridge University Press, 2006, p. 13-39.

DELSOL, M. \& PERRIN, L. Médecine et Biologie: quelle logique? Paris: Masson, 2000. DUTRA, L. A epistemologia de Claude Bernard. Campinas: CLE-UNICAMP, 2001.

ELSASSER, W. Reflections on a Theory of Organism. Baltimore: John Hopkins University Press, 1987.

FUTUYMA, D.; BENNETT, A. The Importance of Experimental Studies in Evolutionary Biology. In: GARLAND, T.; ROSE, M. (eds.). Experimental Evolution: Concepts, Methods, and Applications of Selection Experiments. Berkeley: University of California Press, 2009, p. 15-30.

GLENNAN, S. Mechanisms. In: BEEBE, H.; HITCHCOCK, C.; MENZIES, P. (eds.). The Oxford Handbook of Causation. Oxford: The Oxford University Press, 2009, p. 315-325.

GILBERT, S. Biologia do desenvolvimento. Ribeirão Preto: Sociedade Brasileira de Genética, 1994.

GOLDSTEIN, K. La structure de l'organisme. Paris: Gallimard, 1951.

GOODFIELD, J. El desarrollo de la fisiología científica. México: UNAM, 1987.

GRADMANN, C. Maladies expérimentales: les expériences sur l'animal aux débuts de la Bacteriologie médicale. In: GACHELIN, G. (ed.). Les organismes modèles dans la recherche médicale. Paris: PUF, 2006, p. 75-94.

HEMPEL, C. La explicación científica. Buenos Aires: Paidos, 1979 [1965].

HULL, D. Historical Entities and Historical Narratives. In: HOOKWAY, C. (ed.). Minds, Machines \& Evolution. Cambridge: Cambridge University Press, 1986, p. 17-42.

KUHN T. The Essential Tension. Chicago: Chicago University Press, 1977.

LORENZANO, P. Leyes fundamentales y leyes de la Biología. Scientiae Studia 5:2, (2007), p. 185-214.

LUBCHENCO, J.; REAL, L. Manipulative Experiments as Tests of Ecological Theory. In: REAL, L.; BROWN, J. (eds.): Foundations of Ecology. Chicago: The University of Chicago Press, 1991, pp. 715-733.

MAYR, E. Cause and Effect in Biology. In: Science 134, (1961), p. 1501-1506.

MENZIES, P. The Causal Structure of Mechanisms. In: Studies in History and Philosophy of Biological and Biomedical Sciences 43, (2012), p. 796-805. 
MERLEAU-PONTY, M. La estructura del comportamiento. Buenos Aires: Hachette, 1953.

MITCHELL, S. Unsimple Truths. Chicago: The University of Chicago Press, 2009.

PAPP, D. Filosofía de las leyes naturales. Buenos Aires: Troquel, 1980.

PSILLOS, S. Causation and Explanation. Stockfields: Acumen, 2002.

RAERINNE, J. Stability and Lawlikeness. In: Biology \& Philosophy 28, (2013), p. 833-851.

ROMO, A. Claude Bernard. México: Siglo XXI, 2006.

SMART, J. Philosophy and Scientific Realism. New York: Routledge, 1963.

SOBER, E. The Nature of Selection. Chicago: Chicago University Press, 1984.

THAGARD, P. How Scientists Explain Disease. Princeton: Princeton University Press, 1999.

UJHÁZY, E.; MACH, M.; NAVAROVA, J.; BRUCKNEROVA, I.; DUBOVICKY, M. Teratology - Past, Present and Future. In: Interdisciplinary Toxicology 5: 4, (2012), p. 163-168.

VALERY, Paul. L'homme et la coquille [1944]. In: Varieté III, IV et V. Paris: Folio, 2002, p. 541-569.

VON WRIGHT, H. Explicación y Comprensión. Madrid: Alianza, 1980.

WATERS, K. Causal Regularities in the Biological World of Contingent Distributions. In: Biology \& Philosophy 13, (1998), p. 5-36.

WEBER, M. Philosophy of Experimental Biology. Cambridge: Cambridge University Press, 2004.

WEBSTER, G.; GOODWIN, B. Form and Transformation. Cambridge: Cambridge University Press, 1996.

WOODWARD, J. What is a Mechanism? In: Philosophy of Science 69, (2002), S366-S377. . Making Things Happen: A Theory of Causal Explanation. Oxford: Oxford University Press, 2003.

Agency and Interventionist Theories. In: BEEBE, H.; HITCHCOCK, C.; MENZIES, P. (eds.). The Oxford Handbook of Causation. Oxford: The Oxford University Press, 2009, pp. 234-262.

. Causation in Biology. In: Biology \& Philosophy 25, (2010), p. 287-318.

\section{Endereço postal:}

Gustavo Caponi

Rua Estéves Jr. 605, apto. 1414

88015-130 Florianópolis, SC, Brasil

Recebimento: 01/03/2014

Aceite: 15/04/2014 